
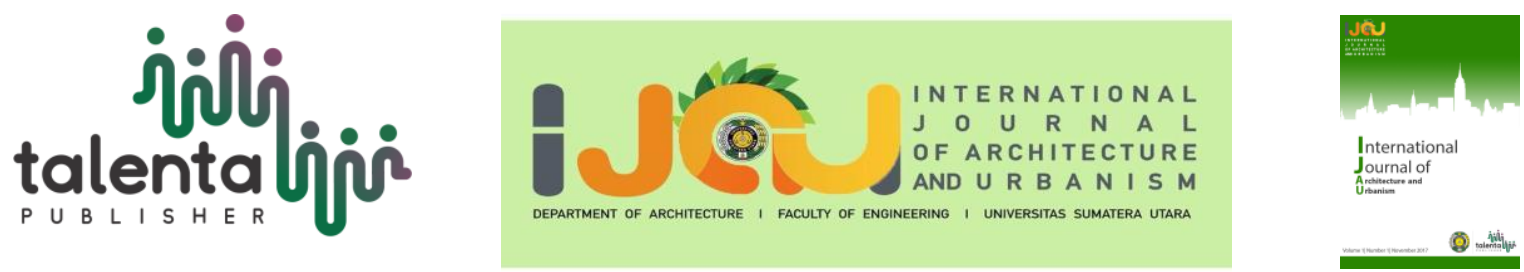

\title{
Arrangement of Special Region in Corridor Dr. Mansyur
}

\author{
Gita Junika Pasaribu ${ }^{1 *}$, Dwi Lindarto Hadinugroho ${ }^{1}$ \\ ${ }^{I}$ Department of Architecture, Faculty of Engineering, Universitas Sumatera Utara, Medan, Indonesia
}

\begin{abstract}
Medan is one of the largest cities in Indonesia after the metropolis of Jakarta also experienced strip development that has shown symptoms in the suburbs. The symptoms can identified from the aspect of land use on the outskirts of Medan in this case usually rural regions are characterized by agrarian areas switching functions to non-agrarian land, seen from the qualities of buildings in the suburbs, almost all buildings distinguished by urban or non-sectoral agrarian in a review of the building characteristics also added about the density of buildings and the number of buildings in a particular area. One of them is the problem that occurred in the corridor Dr. Mansyur. The original road capacity for calm residential traffic can no longer accommodate the dynamics of commercial activities. Traffic congestion, parking vandalism, pedestrian route malfunctioning by street vendors, the emergence of portable stands, and tent stalls on the edge of the road. The consideration will be based on predetermined variables, namely, elements of the city image, specifically paths, boundaries, regions, vertices, and landmarks. For this reason, mixed research carried out through observation and interviews and documentation studies. The results obtained from this study will show how the model of regional arrangement in anticipating the development strip of the city of Medan.
\end{abstract}

Keyword: commercial corridors, strip development, urban sprawl

Received 01-02-2020 | Revised 01-03-2020 | Accepted 12-03-2020

\section{Introduction}

Corridor Dr. Mansyur is one of the passages experiencing strip development. This marked by the planning that is contrary to the essential elements of a proper plan, such as: spending open space, inhibiting pedestrian traffic, getting out of the boundaries of existing development, and so on.

Corridor Dr. Mansyur filled with most road space for motorized vehicles. The original road capacity for calm residential traffic can no longer accommodate the dynamics of commercial activities. Traffic congestion, parking vandalism, pedestrian route malfunctioning by street

\footnotetext{
*Corresponding author at: Department of Architecture, Faculty of Engineering, Universitas Sumatera Utara, Perpustakaan Street, J07 Building, Medan, 20155, Indonesia
} 
vendors, the emergence of portable stalls, and tent stalls on the edge of the road are pictures of changes in designation called strip development of the Urban Sprawl phenomenon [1]. Vehicle users often use the road and sidewalks into spaces that are considered reasonable for parking vehicles. Corridor Dr. Mansyur also experienced a change in function on both sides of the way. The commodification of road space as a commercial area has aroused a shift in the use of house service into commercial services. The change of allotment into the service of trade makes the problem of the negative vitality of the city area.

\section{Literature Review}

The development of commercial strips is a form of urban sprawl that is the development that exceeds the available land use capacity, the more developed land is developed, increasing the degree of urban sprawl [2]. Strip commercial development occurs when commercial area development develops along linear lines along two sides of the arterial road. As is usual urban sprawl, this phenomenon is a sporadic uncontrolled development, poorly visualized, causing congestion when traders and buyers pass the way.

The image of a city can be defined as a mental picture of a city according to its people's average view. There are five elements used to express a public image. According to Kevin Lynch, the image of a city can be divided into five parts, namely path, edge, district, node, and landmark [3].

A corridor is usually on the left and right side of the building; there have been buildings lined lengthwise along the road. Passageways are formed by two rows of masses (buildings or trees) that form a space to connect the two regions/areas of the city neutrally. In other words, a corridor is a space in the form of a plaza, a road, or aisle, extending from a row of buildings, trees, or street furniture to connect the two regions and display the physical quality of the space [4].

\section{Methodology}

This study uses a mix-method method, a research approach that combines or associates qualitative and quantitative forms [5]. This method assumes that in showing direction or giving instructions on how to collect and analyze data and the integration of quantitative and qualitative approaches through several phases of the research process. As for the variables of this research is about the physical condition of the corridor and the condition of facilities and infrastructures using Lynch theory (Table 1). 
Table 1 Research Variable

\begin{tabular}{|c|c|c|}
\hline No & Variable & Indicator \\
\hline 1. & Path & $\begin{array}{l}\text { Type } \\
\text { Function } \\
\text { Shape } \\
\text { Activities formed }\end{array}$ \\
\hline 2. & Edge & $\begin{array}{l}\text { Type } \\
\text { Function } \\
\text { Activities formed }\end{array}$ \\
\hline 3. & District & $\begin{array}{l}\text { Type } \\
\text { Function } \\
\text { Activities formed }\end{array}$ \\
\hline 4. & Node & $\begin{array}{l}\text { Orientation } \\
\text { Type } \\
\text { Function } \\
\text { Activities Formed }\end{array}$ \\
\hline 5. & Landmark & $\begin{array}{l}\text { Function } \\
\text { Shape } \\
\text { History and meaning }\end{array}$ \\
\hline
\end{tabular}

\section{$4 \quad$ Result and Discussion}

This research was conducted in one of the densely populated areas in the city of Medan, which is located in the field of Medan Baru. This area is on Dr. Mansyur, Padang Bulan sub-district, Medan Baru sub-district, Medan, North Sumatra. Initially, Dr. Mansyur is the way of the University of Sumatera Utara (Figure 1).

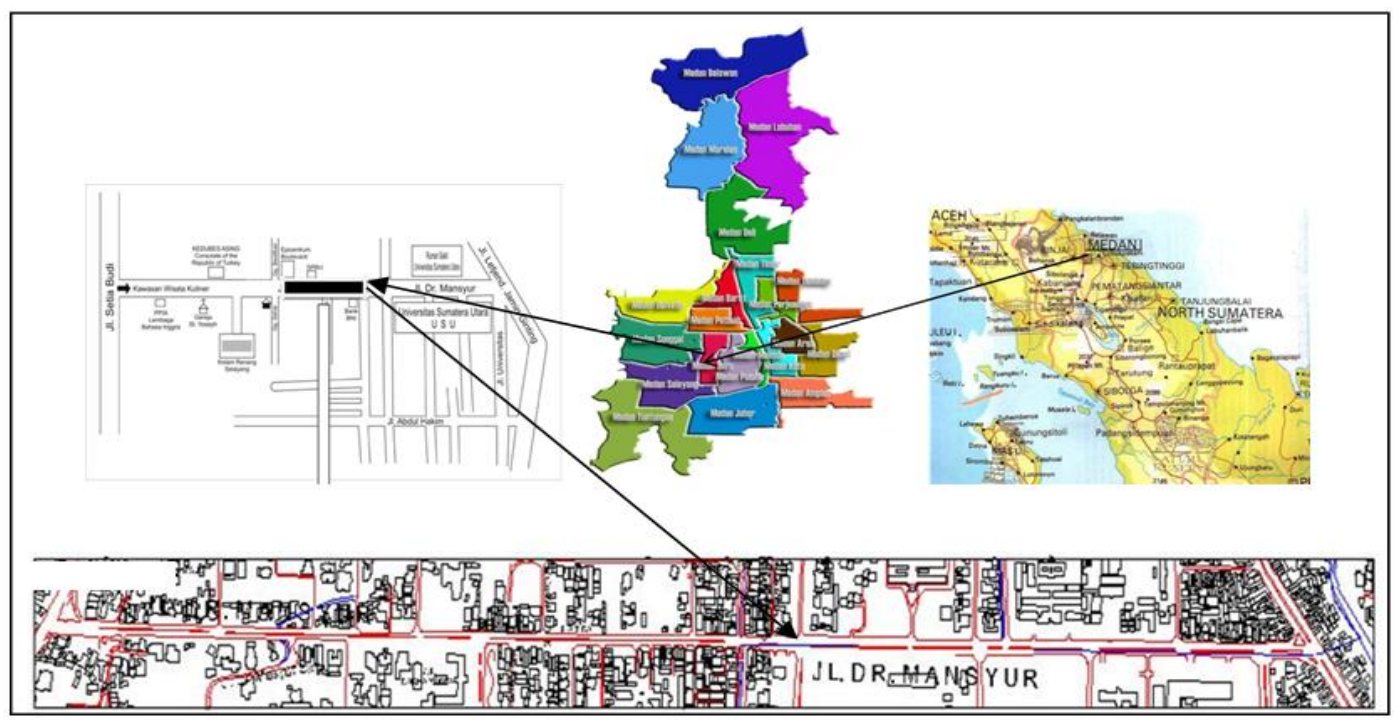

Figure 1 Location of Research Area

This segment is the main route in Dr. Mansyur. This is because this segment is a meeting between Jamin Ginting street and Dr. Mansyur street. This segment is a reasonably busy lane with many private vehicles and public transportation, such as public transport. Unfortunately, in this segment, the need for pedestrian lines is inadequate. Because it will be designed as a proper 
pedestrian so that it can meet the needs of its users. Also, additional elements, such as chairs, will be added (Figure 2).

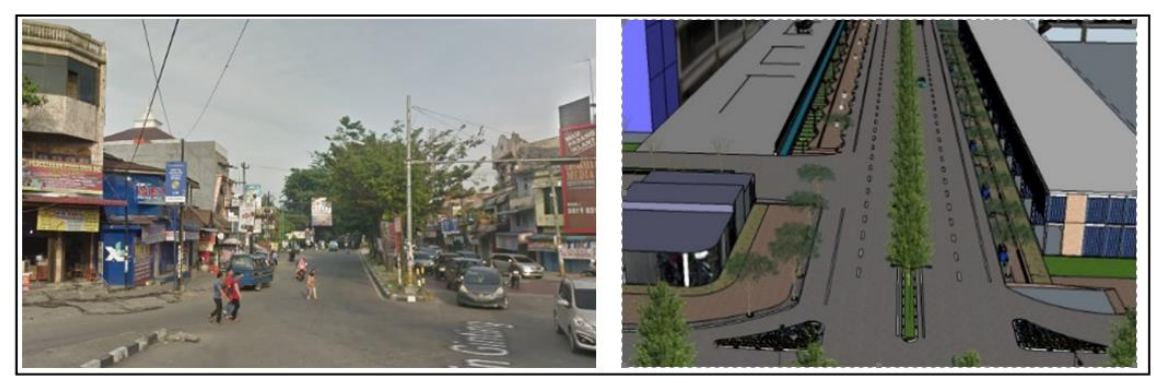

Figure 2 Existing Condition (left) Pre-existing Design (right)

The main principles applied to commercial passages related to this pedestrian route are: creating a sustainable pedestrian path along commercial corridors, develop corridors oriented to pedestrian comfort through structuring the road landscape and harmonious circulation system, develop pedestrian pathways that are easily accessible by cross-gender and different ability people, equipping pedestrian lines with adequate signage and elements, and the dimensions of the pedestrian path are 3-4 m (Figure 3).

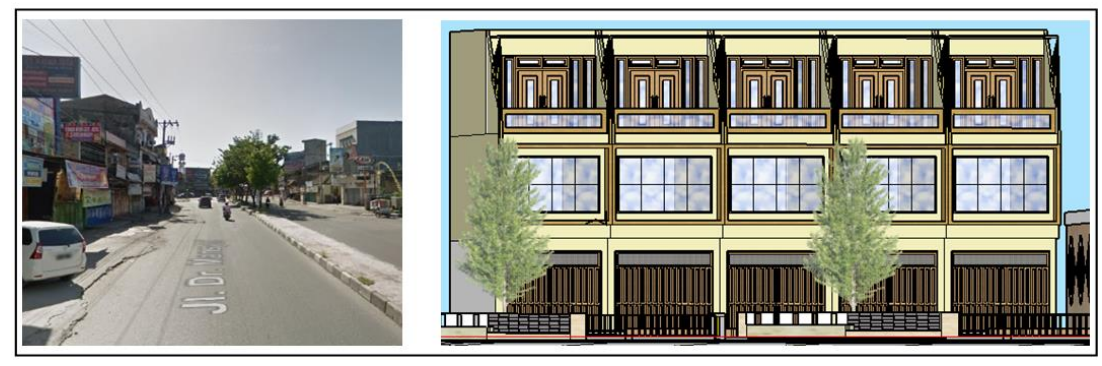

Figure 3 Shopping Conditions (left) and Shop Pre-Design (right)

The condition of the shops in this segment is very chaotic. This because the number of advertisements that are placed carelessly on the building so that it causes shopping buildings in this segment does not look good, so it seems slum. The condition of passage in this segment is also inadequate. So that a shop will be designed with an adequate corridor to meet the needs of its users, it is equipped with vegetation that functions as a shade and barrier to air pollution (Figure 4).

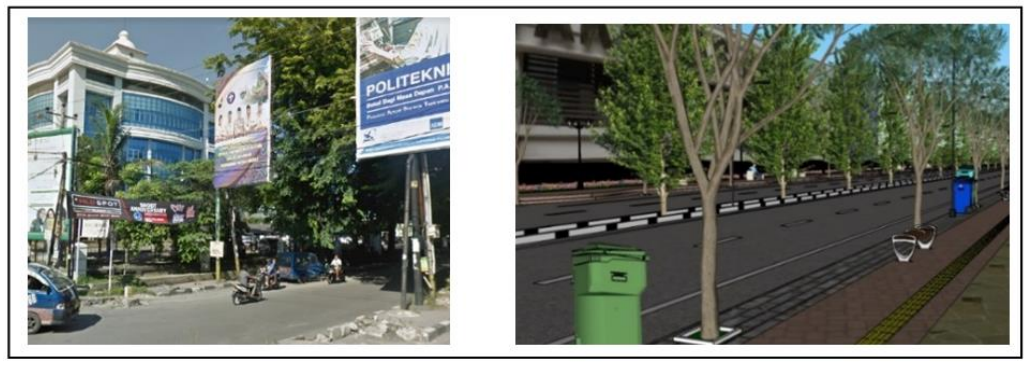

Figure 4 Road condition (left) and Pre-designed road (right) 
Road conditions in this segment are quite good, but street furniture in this segment has not been accommodated. So that roads and corridors that have been provided with street furniture will be designed along with pedestrian ways to increase pedestrian comfort. On the highway corridor, lights will be placed on the road that leads to the side of the way to illuminate the passage and the main road. The distance between lamps is $15 \mathrm{~m}$ (Figure 5).

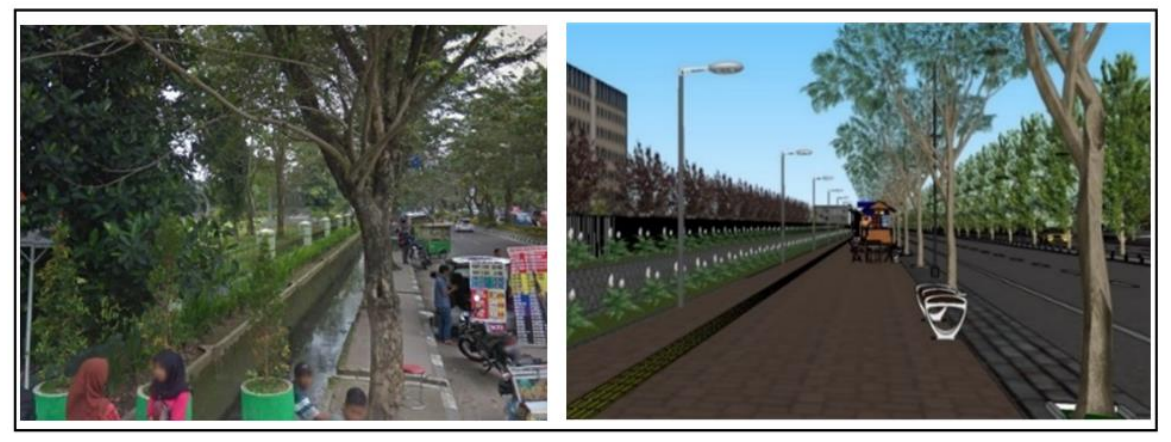

Figure 5 Pedestrian condition (left) and Pedestrian Pre-Design (right)

The main point in this pre-design concept is the provision of locations for street vendors who are not arranged in the corridor of the road along this segment. Where the street vendors choose a place to open a business along the pedestrian lane so the road corridors are not used as they should. The concept in this pre-design emerged from the comparative study and literature review of the State-Madison WI USA road corridor, where the existence of pedestrian lanes and shops/restaurants was not eliminated but was given a boundary between pedestrian paths and shop/restaurant (Figure 6).

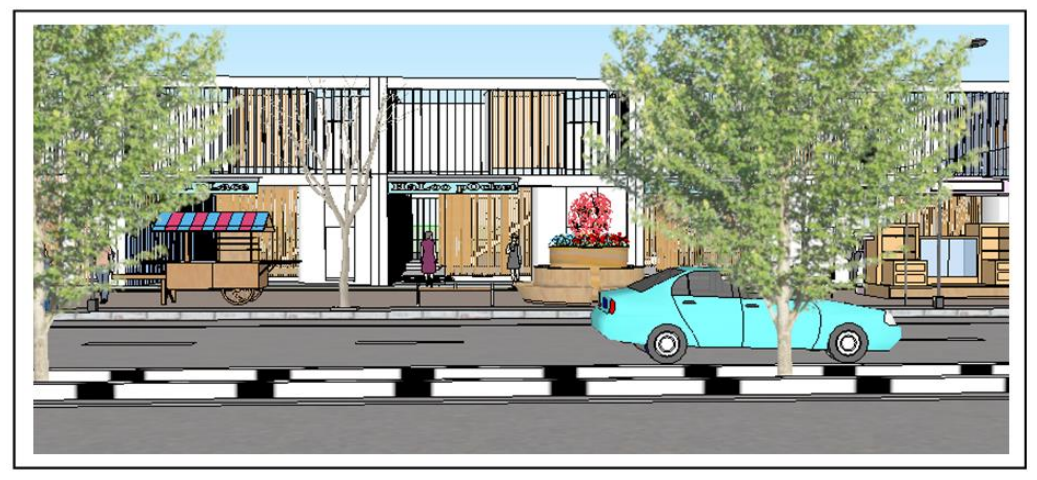

Figure 6 Shop Pre-designed

Principles of Building Mass Display

The addition of new elements or details adapted to the old style. You can add artificial lighting effects to make it more dramatic. Windows and facades are given a unique color touch. Green layout planning still uses the existing tree. Angsana tree that has a function as a shade and maintains the characteristics of the area through vegetation, and using artificial lighting along the corridor (Figure 7). 


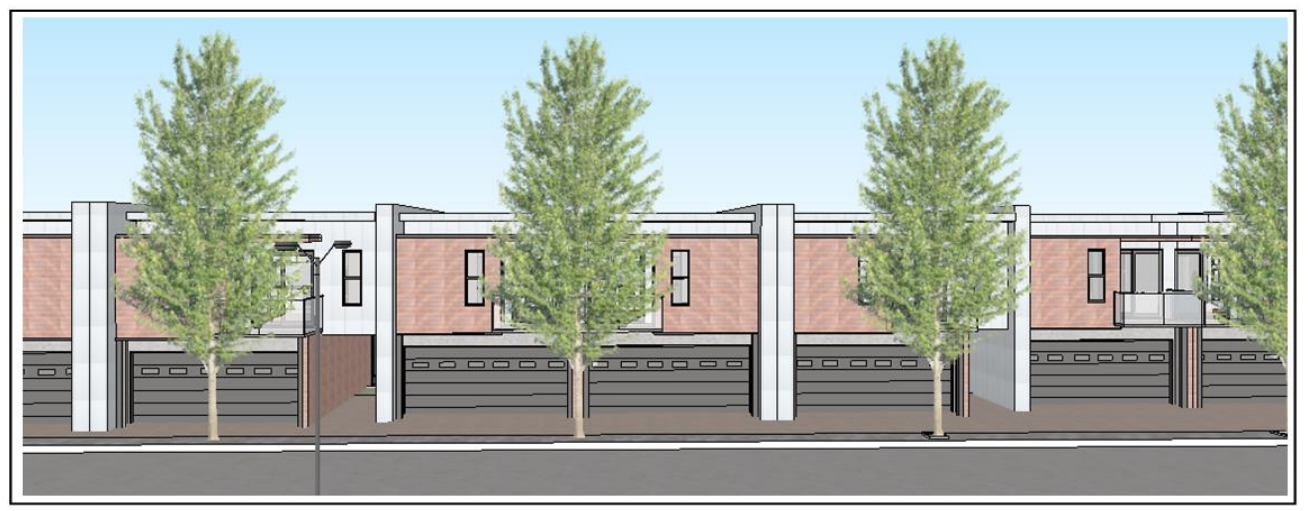

Figure 7 Shop Pre-Design

The condition of the shops in this segment is very chaotic. This because the number of advertisements that are placed carelessly on the building so that it causes shopping buildings in this segment does not look good, so it seems slum. The condition of the corridor in this segment is also inadequate. So that a shop will be designed with an adequate passage to meet the needs of its users; moreover, it was equipped with vegetation that functions as a shade and barrier to air pollution. The plant will be placed on pedestrian ways in the form of shrubs. In this area, street furniture will also be set to increase the comfort of pedestrians. On the main road, street lights will be placed that lead to the side of the way. Garbage bins are placed at intervals of 20 meters apart (Figure 8).

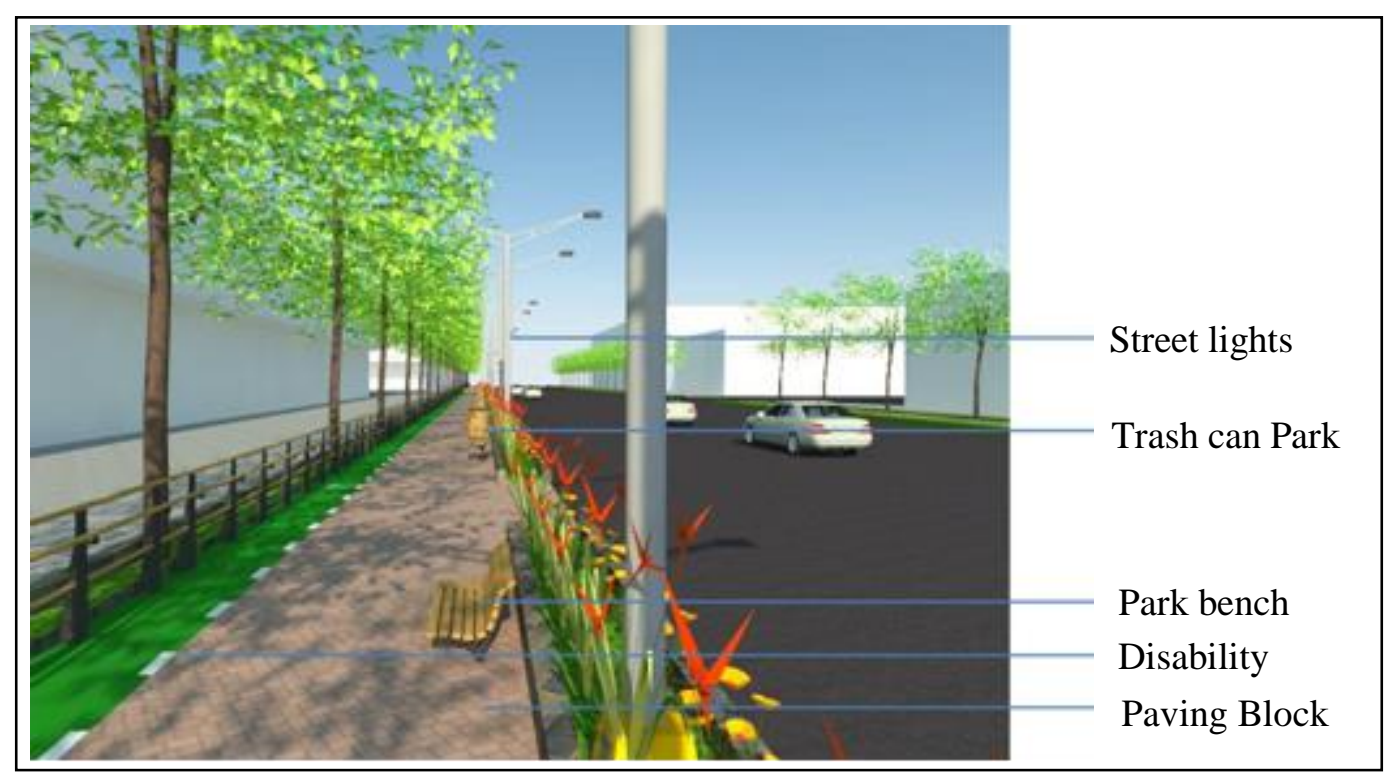

Figure 8 Pre-designed

\section{Conclusion}

In conclusion, structuring commercial corridor area using Lynch's theory in terms of 5 aspects, namely path, edge, district, node, and landmark. Corridor Dr. Mansyur is one of the corridors that is affected by urban sprawl, which is filled by most of the road space for driving, which results in traffic congestion, parking vandalism, pedestrian route malfunction, and so on. So that 
an arrangement is designed, which aims to have the elements in Lynch's theory applied in the corridor Dr. Mansyur.

\section{Acknowledgment}

This research is a study of the arrangement that intended to recommend to the government of a solution to problems that occur because of the malfunctioning of pedestrian lines.

\section{REFERENCES}

[1] Markus Zahnd, Perancangan Kota Terpadu, Teori Perancangan Kota dan Penerapannya. Yogyakarta: Kanius, 1999.

[2] Jochen A.G. Jaeger, René Bertiller, Christian Schwick, Duncan Cavens, and Felix Kienast, "Suitability criteria for measures of urban sprawl," Ecological indicators, vol. 10, no. 2, pp. 397-406, 2010.

[3] Kevin Lynch, The image of the city.: MIT Press, 1960, vol. 11.

[4] Cliff Moughtin, Urban design: street and square.: Routledge, 2003.

[5] John W Creswell and J. David Creswell, Research design: Qualitative, quantitative, and mixed methods approaches.: Sage publications, 2017. 